\title{
Jornadas Desiguais: da mobilidade urbana precária ao home office enquanto opção de fuga do tempo gasto no trânsito na área metropolitana do Rio de Janeiro
}

Journeys Uneven: from precarious urban mobility to the home office as an option to escape the time spent in traffic in metropolitan area of Rio de Janeiro

Journées inégales : de la mobilité urbaine précaire au home office comme une fuite au temps de déplacement professionnel dans la Région Métropolitaine de Rio de Janeiro

Jornadas desiguales: de la precaria movilidad urbana a home office como opción para escapar del tiempo de tránsito en el área metropolitana de Río de Janeiro

Flávia da Silva Souza

\section{OpenEdition}

Journals

\section{Edição electrónica}

URL: https://journals.openedition.org/espacoeconomia/20190

DOI: 10.4000/espacoeconomia.20190

ISSN: 2317-7837

Editora

Núcleo de Pesquisa Espaço \& Economia

Refêrencia eletrónica

Flávia da Silva Souza, «Jornadas Desiguais: da mobilidade urbana precária ao home office enquanto opção de fuga do tempo gasto no trânsito na área metropolitana do Rio de Janeiro», Espaço e

Economia [Online], 22 | 2021, posto online no dia 14 janeiro 2022, consultado o 12 agosto 2022. URL: http://journals.openedition.org/espacoeconomia/20190 ; DOI: https://doi.org/10.4000/ espacoeconomia.20190

Este documento foi criado de forma automática no dia 12 agosto 2022.

Creative Commons - Atribuição-NãoComercial-Compartilhalgual 4.0 Internacional - CC BY-NC-SA 4.0 https://creativecommons.org/licenses/by-nc-sa/4.0/ 


\section{Jornadas Desiguais: da mobilidade urbana precária ao home office enquanto opção de fuga do tempo gasto no trânsito na área metropolitana do Rio de Janeiro}

Journeys Uneven: from precarious urban mobility to the home office as an option to escape the time spent in traffic in metropolitan area of Rio de Janeiro Journées inégales : de la mobilité urbaine précaire au home office comme une fuite au temps de déplacement professionnel dans la Région Métropolitaine de Rio de Janeiro Jornadas desiguales: de la precaria movilidad urbana a home office como opción para escapar del tiempo de tránsito en el área metropolitana de Río de Janeiro

Flávia da Silva Souza

\section{Introdução}

1 Dentre os dilemas da prática cotidiana no contexto da pandemia da covid-19, surge a possibilidade de viabilização das atividades laborais nas residências de maneira remota - o denominado home office. Muito se pensa nos impactos negativos e positivos da adoção dessa prática enquanto opção viável quando o contato e a circulação de pessoas não são recomendados pelos órgãos de saúde (devido alta propagação do vírus).

2 Afinal, o ato de transitar em tempos de pandemia torna-se tão importante quanto no contexto pretérito à mesma, pois não se restringe apenas à acessibilidade aos bens urbanos, mas ganha o significado de práticas socioespaciais que permite a presença e a 
copresença de sujeitos e grupos sociais em diferentes lugares e territórios como corporificação de direitos (BARBOSA, 2015, p. 179).

De antemão, ressaltamos as diferenças conceituas entre o que está sendo considerado por teletrabalho e home office, pois muito tem se discutido sobre como ambos estão sendo categorizados como sinônimos. Segundo Valverde e Souza (2020, p. 2), atualmente, há três tipos de trabalho remoto possíveis, que são (i) o teletrabalho, previsto na Consolidação das Leis Trabalhistas (CLT); (ii) o home office; e (iii) o teletrabalho implementado durante a pandemia, fundamentado na Medida Provisória no 927/2020.

Denota-se, portanto, que, hoje, teletrabalho é a modalidade regulamentada na CLT e o home office é o trabalho remoto realizado eventualmente em casa, sem necessidade de utilização de tecnologias da informação e comunicação (Ibidem, p. 4).

5 Na presente discussão, o teletrabalho é considerado no campo da realização da atividade de modo remoto e que pode ser feito à distância (independentemente do local) amparado por tecnologias de comunicação; home office, por sua vez, foi aqui considerado como o trabalho que é realizado em casa (seguindo o sentido em inglês ao ser traduzido). Os trabalhadores envolvidos na presente pesquisa são compostos por funcionários de escritórios e empresas, que conseguiram realizar suas funções em home office (e se valem do teletrabalho') entre o início da pandemia até meados de dezembro de $2020^{2}$, que possuem domicílio em alguma localidade da área metropolitana do Rio de Janeiro e exerciam, antes da pandemia, suas funções na Cidade do Rio de Janeiro presencialmente.

6 Dentre o histórico de precarização dos trabalhadores, a manutenção deles realizando as suas jornadas em home office torna-se ainda mais cansativas e onerosas. Inúmeras garantias estão sendo omitidas nesse processo, em que a "única" alternativa é a realização do trabalho em domicílio, mas há diversas contradições que fazem os trabalhadores aderirem à ideia do home office como alternativa de fuga do tempo gasto no trânsito em um cenário pós-pandemia. Em contrapartida, tem-se a perda de direitos que eram garantidos na realização dos serviços nos postos de trabalho, como: horaextra, segurança do trabalho, equipamento adequado de escritório para a realização das funções preservando o corpo, entre outros.

7 Esta pesquisa tem por objetivo maior analisar a realização das atividades laborais em casa e o posicionamento dos trabalhadores que exercem suas funções em domicílio, buscando compreender a adesão do home office como uma alternativa de fuga das intensas jornadas no trânsito, e no transporte coletivo $\mathrm{pago}^{3}$, da área metropolitana do Rio de Janeiro. Por primeiro objetivo específico, busca-se compreender os desafios vivenciados pelos trabalhadores que residem em alguma localidade da área metropolitana que atuam na Cidade do Rio de Janeiro; por segundo, objetiva-se elucidar os fatores atrativos e negativos para a realização do home office em 2020; e por terceiro, e último, elucidar, a partir dos trabalhadores, aspectos do funcionamento dos transportes e do home office como alternativa frente a (i)mobilidade.

8 Como tensionamento do termo transporte público ou transporte público coletivo segundo a Lei de Mobilidade Urbana (Lei Federal n. 12587/2012), optou-se por denominar, na presente pesquisa, transporte coletivo pago. Em razão de evidenciar que a denominação pública se torna insuficiente por não ser garantido por direito (acesso livre e gratuito a todos), mas pelas vias das tarifas e das onerosidades congêneres. 
9 E é na relação do trabalhador enquanto ser dotado de direitos, seja no campo dos direitos trabalhistas ou de transporte enquanto um direito fundamental (BRASIL, 1988), que consideramos as perdas, a transposição da figura de cidadão (por intermédio do trabalhador) para usuário (SANTOS, 2014 [1987]) e das negações cotidianas que ele enfrenta diariamente no espaço.

10 A pesquisa se realiza com base em levantamento e leitura de autores que abordam o tema estudado e os assuntos que perpassam a pesquisa; aplicação de questionários semiestruturados, onde buscou-se evidenciar as relações intrínsecas ao home office enquanto opção para fugir da (i)mobilidade urbana do Rio de Janeiro pelo trabalhador; além de análise do material primário levantado com os questionários aplicados remotamente e das fontes secundárias obtidas pelas vias digitais de portais como do Instituto Brasileiro de Geografia e Estatística (IBGE) e Serviço Brasileiro de Apoio às Micro e Pequenas Empresas (SEBRAE).

11 Os questionários semiestruturados mencionados acima foram aplicados remotamente a 10 (dez) trabalhadores ${ }^{5}$, mas é válido ressaltar que o número reduzido se deu em virtude do momento vivido, onde a aplicação foi viabilizada a partir de uma pequena rede de pessoas que possibilitaram o contato de alguns trabalhadores que exercem suas funções na Cidade do Rio de Janeiro. Mas, mesmo em quantitativo reduzido, tal amostra não perde seus atributos de compreensão qualitativa da realidade e reforça mais ainda os desafios de pesquisas elaboradas no decorrer da pandemia.

12 Optou-se por realizar análises qualitativas, por mais que se apresenta a quantificação da amostra, e diluir os resultados obtidos entre as datas de 20 de novembro até 3 de dezembro de 2020, ao longo de todo o debate. Desse montante, 5 (cinco) trabalhadores residem na Baixada Fluminense ${ }^{6} ; 4$ (quatro) residem em bairros da Cidade do Rio de Janeiro; e 1 (um) morador do Município de Niterói (Mapa 01). Buscou-se centrar na questão locacional, localização e tempo de deslocamento, dos trabalhadores, mas é válido ressaltar que a maior parte deles ocupam funções que são realizadas em escritórios e de cunho administrativo/logístico ${ }^{7}$, assim, os possibilitando exercer atribuições em casa. 


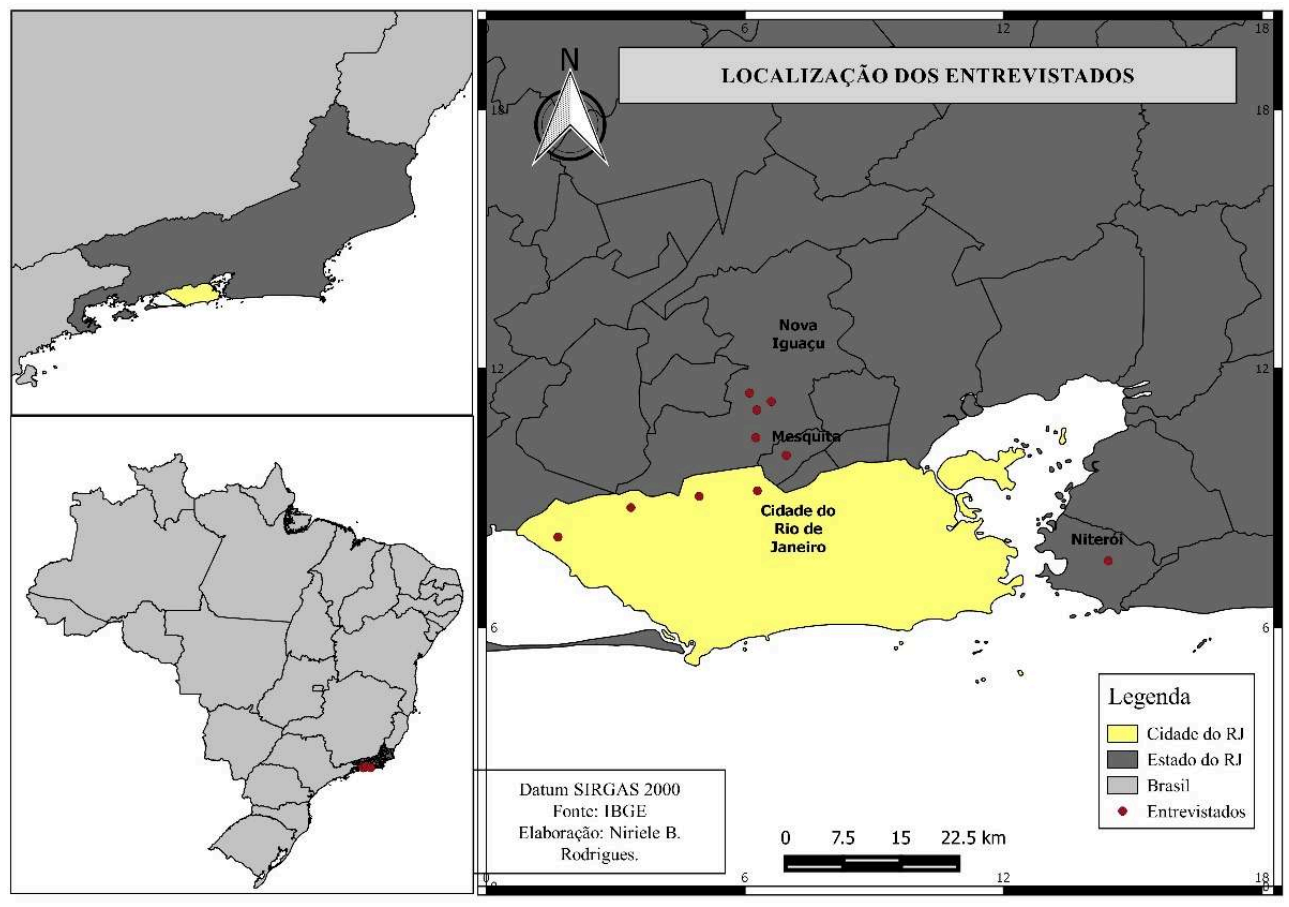

Elaboração: Niriele Rodrigues (2021).

13 Tal perfil de trabalhadores que se dispuseram a responder o questionário, revela um diálogo, em menor quantitativo, com a análise do SEBRAE que foram realizados a partir do Censo do IBGE realizado em 2010. Pois,

De todos os trabalhadores da RMRJ que saem do município de residência para trabalhar, 65,4\% têm como destino a cidade do Rio de Janeiro. Niterói é o segundo município que mais absorve mão-de-obra (11,8\%), seguido de Duque de Caxias (6\%) e Nova Iguaçu $(4,6 \%)$. Estes dois últimos municípios parecem servir como pólos da Baixada Fluminense, tendo em vista que atraem mão-de-obra de municípios vizinhos (SEBRAE, 2013, p. 19).

15 Assim, o caminho realizado buscou evidenciar qualitativamente os desafios de precarização advindos de novas morfologias do trabalho (ANTUNES, 2015) que foram se consolidando a partir da lógica neoliberal, e que ganhou novas formas com a reestruturação produtiva e com a Reforma Trabalhista que alterou a legislação às novas relações de trabalho que estão expressas no texto da Lei $n^{0}$ 13.467/2017. Afinal, o momento atual é caracterizado por um processo de precarização estrutural do trabalho, onde os capitais globais estão exigindo o desmonte da legislação social protetora do trabalho (ANTUNES, 2015, p. 130).

16 E, elucidar os agravamentos vivenciados pelos trabalhadores com a problemática da mobilidade e circulação urbana da área metropolitana; e, das questões oriundas do home office como alternativa a ser viabilizada, ainda enquanto possibilidade, no cenário pós-pandêmico. 


\section{Itinerário laboral e os desafios da mobilidade metropolitana para o trabalhador}

\section{transporte. Essa assume um caráter muito relativo ao crescimento do espaço da} população e ao espraiamento dessa população no espaço físico da cidade. A teia de transporte segue e nasce no Centro. Ou seja, as economias de aglomeração levam as pessoas para o Centro na mesma medida em que as economias de desaglomeração começam a levar as pessoas para longe desse Centro. [...] No caso do Rio de Janeiro, a infraestrutura é pouca e escassa, financeiramente limitada. Então ela cresce em corredores limitados, priorizando as áreas mais nobres. Esse é o caso da Zona Sul, onde se tem mais infraestrutura. Foi nesta área que começou o eixo de saneamento básico, parques, saúde e transporte. ônibus é o prejuízo das camadas mais distantes do centro financeiro e econômico por condensar uma série de atividades, ou seja, dos que estão afastados dos postos de trabalho, entre outros serviços. Isso continua com a manutenção do processo de exclusão social, a economia da cidade é dificultada devido aos impeditivos de acesso à mão de obra e encarecimento dos serviços, pois quem mais sofre com as consequências desse processo de "racionalização" são os passageiros, que pagam preços altíssimos em tarifas para condições péssimas nos modais (Ibidem).

A lógica condiciona os trabalhadores em situações degradantes, e a mobilidade urbana tem grande papel na configuração atual. Com base nisso, acredita-se que a ausência de qualidade e efetividade do transporte coletivo pago, associada à distância física entre os espaços de centralidades e periferias, é responsável pelo fenômeno do tempo imposto que usurpa os tempos de descanso, lazer, estudo, de prazer e de outros mais que nos fazem ser seres humanos plenos (BARBOSA, 2014, p. 195).

21 Há uma distinção entre quem acessa os espaços a partir do transporte coletivo e particular. Para Lévy (2001 [2000], p. 2), a distância-custo, distância e tempo e todas as distâncias complexas que dependem do político, das relações sociais ou do psíquico não devem mais ser colocadas numa posição hierárquica inferior. Ainda segundo o autor, “[...] quando se pergunta aos usuários de automóveis e do transporte público, fica claro que os adeptos de um e do outro não definem o tempo da mesma maneira [...]", em razão disso, acreditamos que há diferenças na percepção dos trabalhadores entrevistados ${ }^{10}$.

Afinal, dentro da situação imposta na sociedade capitalista, de acordo com Barbosa (2014, p. 192), o automóvel nos é apresentado como a síntese prosaica de signo/objeto da velocidade que se encarna na cidade e em nosso próprio corpo, com as rodovias, pistas, avenidas e ruas que se tornam meios de consumo e próprios espaços de exibição de máquinas de velocidade. 
Usufruindo dos dizeres de Lévy (2001 [2000], p. 4), “[...] a posse de um automóvel é um critério economicamente discriminante apenas para uma pequena parcela da população dos países desenvolvidos [...] é porque são poucos móveis que as populaçães mais despossuídas são despossuídas". Desse modo, coincide que muito dos entrevistados não utilizam meios de transporte particular e, quando possuem, optam por economizar custos de manutenção e combustível dos veículos e/ou não querem se preocupar com os fatores logísticos, como estacionamento.

Por isso, pensar na mobilidade exige transformações nas condições urbanas de vida social, dentre eles a inflexão territorial de investimentos públicos em espaços da cidade desprovidos qualitativamente de serviços sociais, educacionais, culturais, segurança e de saúde que promovem e garantem a dignidade dos seres humanos e que devem ser amplamente universalizados na dimensão de raça, classe e gênero (BARBOSA, 2015, pp. 180-181). Barbosa (2015, p. 177) advoga que

Por natureza relacional, a mobilidade nos coloca diante da tensão de relações desiguais de apropriação e o uso do espaço. Desse modo, quando abordamos a questão da mobilidade, necessariamente precisamos inseri-la no contexto de poder (espacial) onde as pessoas e as coisas se movem - e são movidas - entre e intra localidades, lugares e territórios. [...] O debate contemporâneo sobre a mobilidade passa, então, a colocar em causa as espacialidades dos fluxos como ordenamento dos lugares e territórios, assim como vem se configurando como uma esfera pública de disputa política. Afinal, de contas, a mobilidade tem a ver com os lugares que podemos ir e vir, morar e trabalhar, festejar e sermos felizes.

A mobilidade das cidades para o trabalhador é o ponto crucial para as noções de dignidade socioespacial, e é a expressão da satisfação ou insatisfação de locomoção no espaço. E, para quem necessita acessar espaços mais distantes a partir do marco posicional das residências, o desafio complexifica-se pela necessidade de acessar os transportes para ampliar suas espacialidades para o trabalho.

27 Segundo o SEBRAE, o caso da área metropolitana do Rio de Janeiro é emblemático, pois dos 16 milhões de habitantes do estado, conforme dados do Censo Demográfico do IBGE de $2010^{11}, 74 \%$ (quase 12 milhões) residem na Região Metropolitana do Rio de Janeiro. Destes, $62 \%$ com idade entre 15 e 70 anos, trabalham na capital do estado, e por ser a unidade da federação mais metropolitana do país, o forte fluxo de pessoas entre as periferias e o centro da cidade do Rio, torna a questão da mobilidade urbana crucial para se discutir o mercado de trabalho e o desenvolvimento da região (SEBRAE, 2013).

28 Há muito tempo, a mobilidade da área metropolitana do Rio de Janeiro é observada a partir dos indicadores de percentual da renda salarial gasta com transporte público e tempo de deslocamento de casa ao trabalho. Pode ser considerada uma das piores do Brasil (PERO e MIHESSEN, 2013, p. 46), pois é onde se gasta, em média, maior tempo no trajeto de casa ao trabalho, além do desperdício de tempo e dinheiro.

É válido apontar a imobilidade espacial em diversas localidades da área Metropolitana do Rio de Janeiro, seja no campo de ausência de serviços de transporte coletivo ou no baixo quantitativo ofertado. Lagos $(2007$, p. 286) apresenta elementos para afirmar que a intensidade da mobilidade diária resulta na desarticulação entre a hierarquia espacial de centros e subcentros econômicos, onde o transporte coletivo e a dinâmica imobiliária influenciam em uma (i)mobilidade espacial entre casa-trabalho. 

meios de transporte individual: as políticas públicas praticamente determinam a instalação de um sistema que impede o florescimento dos transportes coletivos, enquanto o planejamento urbano convencional trabalha a partir das mesmas falsas premissas e fica dando voltas em torno de si mesmo, sem encontrar uma saída que seja interessante para a população (Ibidem, p. 63).

37 É evidente que há condicionantes do mercado e incompletude das ações do Estado no que concerne às políticas de transporte, que operam de maneira restrita na mobilidade urbana, pois essas restrições são mais severas quando se trata de grupos sociais mais vulneráveis e que habitam em territórios mais precários (BARBOSA, 2015, p. 180). Tudo isso dá os sentidos da mobilidade metropolitana, onde que a ineficiência e insuficiência são atributos quase que permanentes para se definir a malha de transporte. 
38 O que foi apresentado anteriormente relacionado ao trabalhador gesta a dicotomia entre custo e tempo das distâncias que estão inscritas em relações sociais complexas e profundamente desiguais, sobretudo no que concerne aos sujeitos que indiscriminadamente acaba sendo denominado de usuários (BARBOSA, 2015, p. 183).

39 Entre os diversos dilemas da mobilidade urbana e o direito ao transporte, há uma imobilidade espacial dos trabalhadores. Por conseguinte, eles se veem obrigados a aderir a uma prática que nega seu status de trabalhador em prol de uma mobilidade que não atende suas necessidades de circulação. Para Lévy (2001 [2000], p. 5), surge então um paradoxo: enquanto a mobilidade deveria ser estimulada a fim de oferecer aos referidos indivíduos as oportunidades, muitas vezes gratuitas, que permitem o acesso ao conjunto dos lugares da cidade, este tipo de pensamento nos encerra numa desastrosa imobilidade.

Discute-se muito acerca dos trabalhadores no ambiente de trabalho, mas é a partir da realização de suas práticas que podemos pontuar e elucidar se de fato o bem-estar é vivenciado pelos trabalhadores na mobilidade urbana e se isso será atingido pelo home office. Entende-se bem-estar como a qualidade de vida (moradia digna, saúde, segurança, alimentação adequada, entre outros fatores mais) obtida e que pode ser proporcionada ao trabalhador nas esferas laborais e para além dela.

41 O imaginário das atividades laborais em domicílio e o uso dos meios de transporte particular acabam não suprindo as demandas básicas do trabalhador, e tal lógica não se encontra alheia à realidade imersa nas relações desiguais na cidade regida pela lógica neoliberal (HARVEY, 2014) e que vem sofrendo transformações da precarização estrutural do trabalho a partir da reestruturação produtiva em praticamente todo universo industrial e de serviços (ANTUNES, 2005, p. 125).

O neoliberalismo apropria-se da flexibilização do trabalho e da precarização condições impostas para o trabalhador, segundo Harvey $(2014$, p. 86) o resultado disso se traduz em baixos salários, crescentes insegurança no emprego e, em muitos casos, perdas de benefícios e de proteção ao trabalho. $O$ autor ainda afirma que dado o violento ataque de todas as formas de organização do trabalho e aos direitos dos trabalhadores, a que se adiciona o amplo recurso a reserva de mão de obra numerosa altamente desorganizada em diversos países, com isso fica a impressão de que o controle do trabalho e a manutenção de elevado grau de exploração do trabalho têm se constituído desde o começo em um componente essencial de neoliberalização (HARVEY, 2014, p. 86).

43 A lógica ancorada no cerne neoliberal, modificada os processos de reestruturação produtiva, remonta um cenário para os trabalhadores informais, formais e digitais. Onde o maior desafio encontra-se no campo da obtenção da renda para a sobrevivência e manutenção/incorporação de garantias trabalhistas.

\section{Do trabalhador precarizado à mobilidade precária}

44 A dualidade entre trabalho formal e informal ganha contornos maiores e complexificase, pois o imaginário de trabalho formal está no campo de garantias trabalhistas e segurança laboral. O teletrabalho implementado na pandemia põe em dúvida a realização das funções laborais que de fato estão cumprindo os requisitos legais e a integridade (física e mental) dos trabalhadores. 
45 Como foi apresentado em outro momento, sobre as distinções jurídicas dos termos em uso na presente pesquisa, é válido elucidar que, com a regulamentação do teletrabalho pela Reforma Trabalhista, a distinção fica ainda mais clara, pois o teletrabalho passa a ter requisitos próprios, como, por exemplo, a prestação de serviços fora do estabelecimento do empregador, a necessidade de anuência do empregado para adoção desta modalidade, a necessidade de se fazer constar a implementação em termo aditivo ao contrato de trabalho, entre outros (VALVERDE e SOUZA, 2020, pp. 3-4).

46 É de conhecimento que as garantias dos trabalhadores são retiradas em ações cotidianas, que não fornecem meios adequados de realização da função e de condições para chegar/regressar da mesma. Mas os questionamentos ancoram-se na noção dos trabalhadores sendo subordinados com o teletrabalho e do home office, usurpando o espaço da casa (e gerando custos) e ultrapassando todas as medidas de segurança do trabalhado ao se distanciar do ambiente formal.

47 Muitos dos trabalhadores entrevistados na presente pesquisa observam a opção do home office como uma alternativa positiva à condição imposta pelo vírus e no cenário posterior, representando uma nova tomada de decisão necessária para não se perder tempo no trânsito, evitar custos com o transporte (coletivo e/ou particular) e, até mesmo, de manter uma rotina mais familiar ao estarem em casa com maior (ou quiçá melhor) proximidade.

48 A prática do Home office foi considerada benéfica para $70 \%$ dos trabalhadores entrevistados dentre distintos argumentos, como economia do tempo de deslocamento, mais tempo para atividades pessoais, menos estresse, sendo que alguns até possuem estrutura razoável para realização da prática em casa e os evita de sair do domicilio; os outros $30 \%$ alegam que não, pois há problemas de espaço e infraestrutura para a prática - argumento também apontado por outros entrevistados que consideram que sim, mas ainda reclamaram da conexão ofertada pelas empresas de internet.

49 Muitas das respostas estão no campo externo aos direitos que podem estar sendo suprimidos por uma melhor, mas aparente, comodidade laboral ou que esteja dentro de uma logística individual de meios adequados para a realização do teletrabalho em seus domicílios. Em uma outra pergunta acerca das diferenças entre o trabalho realizado antes da pandemia e no decorrer da mesma, pode-se constatar que a realização das atividades na empresa é provida de melhores recursos, como suporte de Tecnologia da Informação (TI), internet mais veloz, contato interpessoal entre os colegas de trabalho (agora feito de maneira digital) que ajudava no fortalecimento das equipes, cumprimento de horário de almoço/descanso (o que se perde fora de um ambiente formal), cumprimento de uma jornada mais rigorosa dentro do tempo estabelecido nos contratos de serviços; mas uma pequena parcela dos trabalhadores alegam melhorias, em razão de um ambiente menos estressante e até alegaram que não vê mudanças.

50 Antunes, 0ancorado pela noção de jornada de trabalho em Marx, torna compreensível tal relação. Pois, para o autor, a jornada de trabalho possui uma barreira máxima que não é prolongável acima de um certo limite, e esta barreira máxima está duplamente determinada pela barreira física da força de trabalho, afinal, “[...] uma pessoa, durante um dia natural de 24 horas, só pode despender um determinado quantum de força vital. [...] Para além de uma barreira física, o prolongamento de trabalho choca com barreiras morais" (ANTUNES, 2013, p. 13). 
51 Para Antunes (2013, p. 20), o capital derruba barreiras máximas da jornada de trabalho, não só no campo moral, mas também puramente física em razão dele usurpar o tempo para crescimento do trabalhador, desenvolvimento saudável de conservação do corpo, além de constantemente tentar negar a fixação de uma jornada de trabalho normal que é resultado de uma luta de muitas centenas de anos entre capitalistas e operários (Ibidem, p. 28).

52 A lógica imposta aos trabalhadores rouba o tempo requerido para o consumo de ar livre e luz solar, rouba o tempo da refeição e incorpora-o, sempre que possível, ao próprio processo de obtenção de lucros (ANTUNES, 2013, p. 20). No home office, o trabalho suplementar (conhecido popularmente como horas extras) é suprimido sob o argumento de que não há um controle rígido de jornada de trabalho (feito por intermédio de controle de ponto) apto a mensurar a quantidade de serviço prestado além do estabelecido para a jornada normal de trabalho. Segundo Valverde e Souza (2020, p. 5; grifo das autoras):

54 Contudo, ao fazer menção ao artigo 62, III da CLT, a MP atraiu a todos esses casos de trabalho remoto o regramento do teletrabalho no que concerne à inaplicabilidade do Capítulo da "Duração do Trabalho" da CLT a estes empregados. Com isso, acaba-se atraindo também a discussão acerca do pagamento de eventuais horas extraordinárias a esses empregados. Isso porque, há quem entenda que ao excluir os teletrabalhadores das disposições do Capítulo "Da Duração do Trabalho" da CLT, esses trabalhadores, ainda que controlados por seus empregadores, não fariam jus a percepção de horas extras, intervalo intrajornada e interjornada, hora noturna e adicional noturno.

55 Referidas autoras também questionam se na prática haverá de fato diferenças entre os diversos tipos de trabalho remoto em tempos de quarentena, ainda afirmando que é certo que algumas atividades terão que ser realizadas em horário comercial, muitas vezes envolvendo ligações, videoconferências ou mensagens em tempo real, enquanto outros empregados terão maior flexibilidade, assemelhando-se aos teletrabalhadores clássicos.

56 As jornadas desiguais podem ser percebidas na escala do ambiente de trabalho/home office e da cidade, onde algumas justificativas retiram pequenos e consideráveis direitos para uma parcela dos trabalhadores. Muitos dos argumentos levantados estão no campo de como encaram individualmente a jornada em suas residências. Com isso, as garantias no campo coletivo vão ficando cada vez mais diluídas por benesses individuais, e sob a ótica de que cada um observa as limitações e possibilidades das suas experiências.

57 Mas, ao passo em que o ambiente do trabalho é transposto para dentro de suas casas, os limites da vida pessoal e laboral se tornam quase indissociáveis, com os custos de se manter em atividade em casa acabam sendo, majoritariamente, custeados pelos próprios funcionários na maioria das vezes ou pelo empregador em alguns casos. Em comum acordo com os dizeres anteriores, pode-se observar que os custos são reduzidos para o empregador com o não fornecimento de equipamentos e regulamentações laborais (vide a segurança do trabalho), mas pode-se observar na regulamentação na consolidação da CLT, que

Art. 75-D. As disposições relativas à responsabilidade pela aquisição, manutenção ou fornecimento dos equipamentos tecnológicos e da infraestrutura necessária e adequada 
à prestação do trabalho remoto, bem como ao reembolso de despesas arcadas pelo empregado, serão previstas em contrato escrito.

Parágrafo único. As utilidades mencionadas no caput deste artigo não integram a remuneração do empregado.

Art. 75-E. O empregador deverá instruir os empregados, de maneira expressa e ostensiva, quanto às precauções a tomar a fim de evitar doenças e acidentes de trabalho.

61 Acerca do fornecimento de suporte financeiro e equipamentos dos empregadores para a realização das funções nos domicílios, foi levantado que $70 \%$ dos entrevistados alegaram ter algum tipo de suporte, por menor que seja. Dentre as respostas, a maioria consiste no mobiliário de escritório, como computador e cadeira. Um trabalhador alegou ter recebido mil reais em parcela única no início da pandemia; e apenas um trabalhador diz receber regularmente suporte de papel, ajuda de custo com internet, luz, entre outros.

62 A Medida Provisória estipulou que deverá ser firmado contrato tratando do tema, no prazo de 30 dias, e que, na hipótese de o empregado não possuir os equipamentos necessários e adequados à prestação do teletrabalho, dois serão os cenários possíveis: poderá o empregador fornecer os equipamentos em regime de comodato e pagar pelos serviços de infraestrutura, sem que isso caracterize verba de natureza salarial, ou, não o fazendo, o empregado, impossibilitado de trabalhar, terá sua jornada computada como tempo à disposição do empregador (VALVERDE e SOUZA, 2020, p. 6).

63 E, ainda sobre a mesma questão, 30\% alegaram que não receberam nenhum tipo de suporte para se manter trabalhando em home office desde o início da pandemia no país, contrapondo os $70 \%$ que dizem receber algum tipo de suporte, por mais que seja uma resposta positiva, os recursos fornecidos são insuficientes dentre o quantitativo analisado.

64 Destaca-se, aqui, que desigualdades laborais, aprofunda-se em funções que não exigem nível superior, apenas escolaridade básica ou sem escolaridade, por mais que o texto não se debruce muito sobre eles, pois não é a intenção na presente pesquisa, é válido destacar que a precarização é uma condição muito mais evidente na jornada laboral e que as suas funções não lhe garantiram a realização do home office, mas os deixaram no limbo entre a contaminação do vírus e desemprego.

\section{Implicações do Home Office como alternativa de fuga da mobilidade insuficiente}

Durante a pandemia, observou-se o crescimento do home office no país, numa tentativa de diminuir o perigo de contágio da população pelo coronavírus e, mesmo tendo se passado meses, o que era emergencial foi virando, em alguns setores, oficial (ROLNIK, 2020). Ao se realizar isso, faz-se da casa escritório; inevitavelmente, se perde o espaço da casa, de modo que uma parte do ambiente de convívio familiar é sequestrada pelas necessidades da empresa ou órgão público empregador, que transfere seus custos de aluguel ou Imposto sobre a Propriedade Territorial Urbana (IPTU) para seus empregados e para as famílias destes empregados (Ibidem).

66 A relação dita causal, para evitar ou perder o tempo útil de trabalho ou descanso no transporte, está posto como saída permanente com a adoção do home office. A 
mobilidade realizada nas grandes metrópoles é argumento favorável para se "pregar" uma implementação definitiva do home office às custas da submissão do trabalhador, pois é de conhecimento que muitas empresas economizam e economizarão custos ao fechar estabelecimentos (estruturas físicas congêneres) nos centros comerciais de grandes cidades e com gastos que seriam destinados à manutenção.

67 Ao longo de todo o texto apresentou-se que os direitos e garantias estão sendo negados para que o empregador tenha menores gastos e prejuízos, e esse é um fato constatado desde a Reforma Trabalhista de 2017 que alterou a CLT ao reduzir custos com os trabalhadores que terão que trabalhar mais. Afinal, acidente doméstico no horário de trabalho poderá ser considerado acidente de trabalho? Ainda não se sabe ao certo, mas a implementação do home office deverá acompanhar uma legislação vigente e o cumprimento da mesma - descortinar as ações realizadas em período atípico.

68 Com a pandemia tudo se torna ainda mais complexo, e com a questão da mobilidade não seria diferente, "desde o início do isolamento social, em março, em função da pandemia do novo coronavírus, o poder público determinou que trens, barcas, metrô, ônibus municipais e intermunicipais, assim como o BRT, diminuíssem a lotação" (RADIO AGÊNCIA NACIONAL, 2020). Ou seja, toda infraestrutura de transporte coletivo preteritamente insuficiente torna-se ainda mais parca para a população trabalhadora, entre aqueles que nunca pararam de trabalhar presencialmente.

69 Rolnik (2020) evidencia que por se tratar de uma fatia tão pequena da sociedade, não se pode atribuir somente ao teletrabalho a diminuição da circulação que ocorreu durante a pandemia (as escolas e universidades fechadas, por exemplo, são um fator importantíssimo nessa equação), a esmagadora maioria dos trabalhos continuou e continuará sendo presencial, especialmente os de baixa remuneração, cujos trabalhadores fazem viagens de longuíssima distância, cruzando a cidade das periferias até o centro.

70 A mobilidade urbana insuficiente promove a implementação do home office, afinal, criamos condições urbanas de transporte tão hostis e "indigestas" que o próprio trabalhador prefere optar por colocar-se em condições inadequadas ao ter que encarar o trânsito para acessar os locais de serviços na Cidade do Rio de Janeiro (por mais que não percebam que diretos estão sendo cerceados).

71 Boa parcela dos trabalhadores que responderam ao questionário afirma que o home office (em conjunto com teletrabalho) é uma alternativa viável para um período póspandemia. Cerca de $60 \%$ acreditam que sim, enquanto possibilidade, enquanto $40 \%$ afirmam que sim (como certeza). As afirmativas e possibilidades de permanência da prática são vistas em razão de ser uma realidade já implementada por outros países, devido ao bom resultado/produtividade dos funcionários na pandemia, por ser uma prática lucrativa/econômica para as empresas, por considerarem que a prática é benéfica para ambas as partes envolvidas na relação laboral, além de outras viabilidades.

72 Em associação com outra questão posta nos questionários, foi possível identificar se os trabalhadores acreditam que os seus empregadores irão aderir à prática em um cenário posterior a pandemia. Muitos dos trabalhadores veem a situação como uma possibilidade consistente de realização; $40 \%$ acreditam que sim, 30\% não sabem dizer e os outros $30 \%$ acreditam que não. É válido destacar que, a depender do tipo de trabalho, o home office não pode ser considerado uma opção e, com isso, uma pequena parcela da população trabalhadora realiza a mesma em caráter permanente em todo período de 
pandemia com cerca de 7,9 milhões (Gráfico 01), segundo o gráfico do IBGE é possível reconhecer a permanência dos trabalhadores de modo remoto após mais de 4 meses em quarentena.

Gráfico 01: Gráfico do quantitativo de trabalhadores de modo remoto entre 03/05 e 26/09/2020 no Brasil

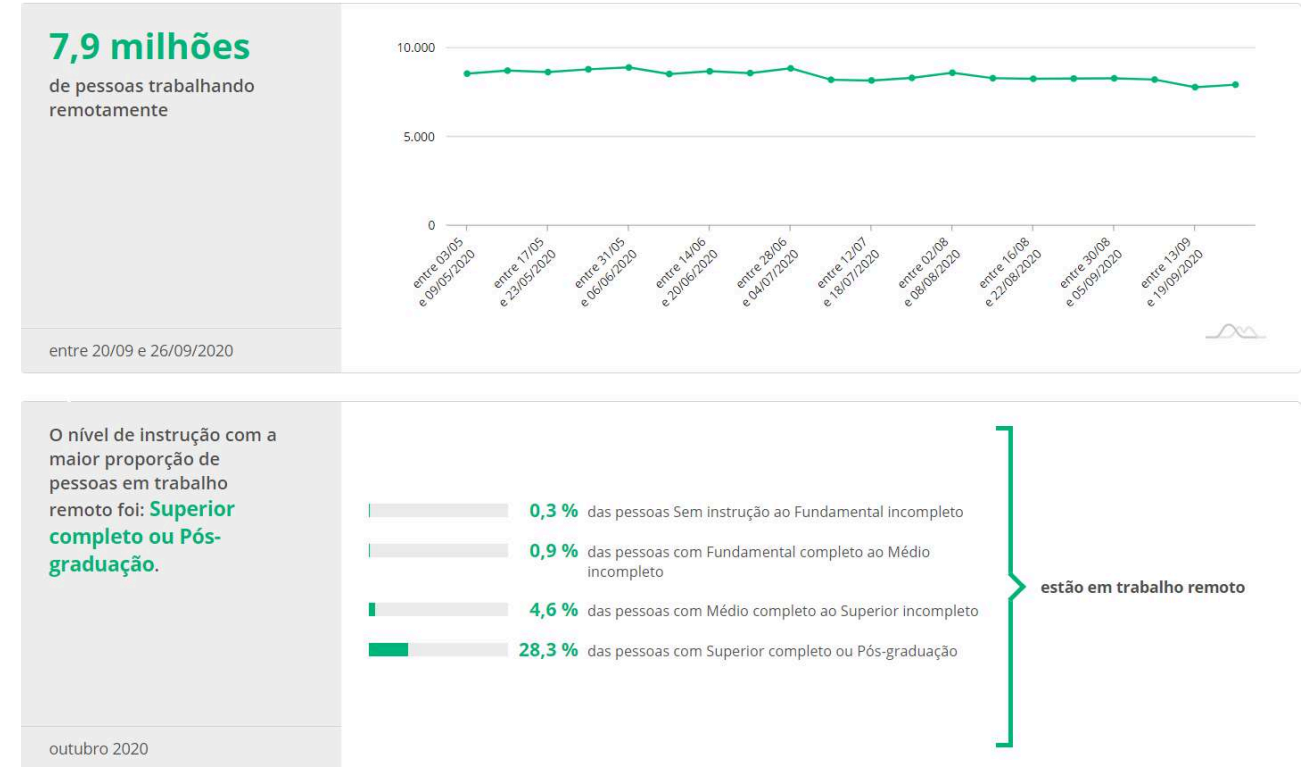

Fonte: PNAD COVID-19/IBGE (2020)

73 É válido destacar uma das respostas obtidas com a aplicação dos questionários, onde um trabalhador identificou que, em funções de baixa instrução como a que realiza, o home office é uma alternativa para a situação pandêmica, mas que pode ser uma realidade para os trabalhadores que exerçam funções de liderança ou tomada de decisão. Isso revela que quem mais ocupa os cargos de home office não são os trabalhadores com baixa instrução, mas sim os com melhor instrução, no qual representa $28,3 \%$ dos trabalhadores de modo remoto no país (Quadro 01), segundo o IBGE.

Quadro 01: Quadro dos níveis de formação que realizam o trabalho remoto no Brasil

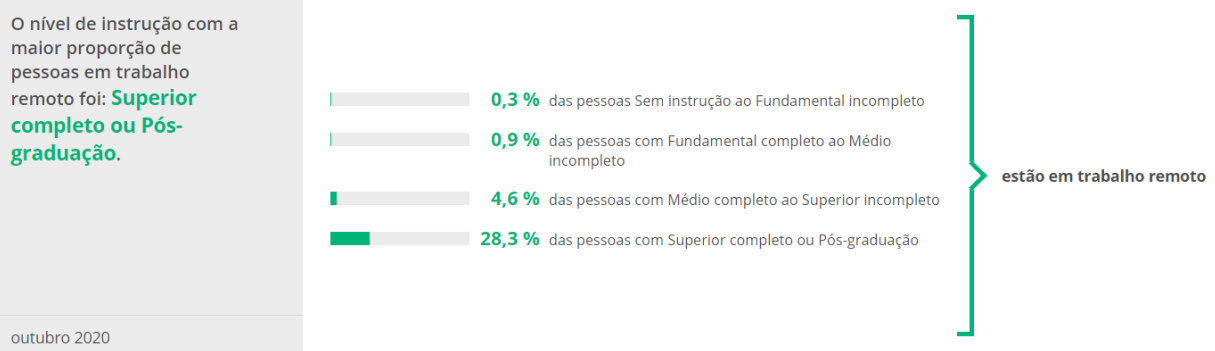

Fonte: PNAD COVID-19/IBGE (2020)

74 Em vista de comprovar a hipótese aqui levantada, que intitula a presente pesquisa, foi levantado nos questionários se os trabalhadores consideram o home office como uma alternativa viável frente ao dispêndio de tempo no trânsito a caminho do trabalho ${ }^{13}$. Por unanimidade, os trabalhadores entrevistados alegam que é uma alternativa para 
não perder horas no trânsito da Cidade do Rio de Janeiro; as justificativas perpassam sempre pela comodidade domiciliar, para evitar a perda de tempo em longas jornadas no transporte coletivo e pela conversão do tempo no trânsito em qualidade de vida.

75 Como afirmativa do que foi dito anteriormente, pode-se levantar que apenas 1 (um) dos entrevistados se vale do carro, 1 (um) somente do ônibus, 1 (um) somente do trem, 6 (seis) necessitam transitar por mais de um meio de transporte e 1 (um) utiliza três meios distintos de transporte. A média de tempo diário gasto no trânsito entre os trabalhadores varia entre $1 \mathrm{~h} 30$ e $2 \mathrm{~h}$ entre os trabalhadores que residem em alguma localidade da Cidade do Rio; já para os trabalhadores residentes na Baixada Fluminense, entre 2 horas e 4 horas em situações "normais". Pode-se detectar nas respostas desafios de mobilidade, como descarrilhamento do trem, baixo quantitativo de transportes pra determinados horários, atrasos devido à logística das ditas conduções, entre outras.

76 De acordo com o SEBRAE (2013, p. 10), tendo em vista o total de pessoas que mora fora da cidade do Rio, durante o dia, entre 6 horas da manhã e 6 da noite, a capital recebe mais de 2 milhões de pessoas, ocorre um aumento da população da cidade do Rio em aproximadamente $30 \%$, já que poucos são moradores da cidade do Rio que saem do município para trabalhar. Tal dado, revela as confluências entre o estudo aqui realizado com a pesquisa do SEBRAE, ao reforçar que os trabalhadores moradores da cidade do Rio ocupados gastam mais de 60 minutos no trânsito para o trabalho, já para os moradores das periferias, o tempo de deslocamento sobe mais ainda, resultado que é esperado, pois dentre os moradores da periferia que trabalham, $41 \%$ estão ocupados em municípios diferentes da residência (2013, p. 11).

77 Existe uma distinção entre os trabalhadores que responderam os questionários: os que estão fora dos limites da Cidade do Rio de Janeiro enfrentam os desafios do transporte coletivo pago dos espaços considerados periféricos, onde há uma dupla precarização das condições para quem utiliza o mesmo e a questão da distância geográfica (perdem muito mais tempo no trânsito).

78 Com a decisão de adoção do home office como fuga do trânsito, torna-se injustificável pensar em abdicar de um direito por outro, pois há vigente a garantia dos direitos trabalhistas que estão previstos no artigo $7^{\circ}$ da Constituição Federal ao declarar que "são direitos dos trabalhadores urbanos e rurais, além de outros que visem à melhoria de sua condição social [...]" (BRASIL, 1988). Ou seja, tais direitos são inalienáveis e não estão alheios ao trabalhador. $O$ direito ao transporte também está previsto em pé de igualdade com os outros direitos fundamentais e não perde seu status em vista de outros.

79 Art. $6^{\circ}$ São direitos sociais a educação, a saúde, a alimentação, o trabalho, a moradia, o transporte, o lazer, a segurança, a previdência social, a proteção à maternidade e à infância, a assistência aos desamparados, na forma desta constituição (BRASIL, 1988).

80 O fato gerado causa o que é conhecido no meio jurídico como conflito de direitos, situação ocorrida quando um fato ocasiona conflito entre tipos distintos de prerrogativas, não se podendo precisar qual direito prevalece (MASSON, 2016, pp. 208-209).

81 Rolnik (2020) afirma que o teletrabalho e o home office não irão salvar nossa combalida mobilidade urbana, pois possíveis melhorias significativas na circulação exigem a adoção de políticas públicas e mudança radical nos modelos adotados pelas gestões para o transporte coletivo e mobilidade como um todo. Exigem investimentos claros no 
aumento da oferta de transporte coletivo de passageiros, no transporte ferroviário de carga, na redução da dependência de carros e caminhões, na substituição imediata dos motores a diesel dos ônibus, entre outras medidas, ao invés da adoção do teletrabalho que vai operar este milagre na nossa mobilidade (Ibidem).

A solução ou uma suposta saída nos revela caminhos de (re)pensar a urbanização e mobilidade adotada nas grandes metrópoles, em vista dos modais de transporte coletivo pago saturados e insuficientes para a realidade observada na área metropolitana do Rio de Janeiro. Se o home office está sendo considerado como uma alternativa viável para os trabalhadores no pós-pandemia, dentro de uma lógica que nega boa parte dos seus direitos laborais e responsabilidades empregatícias, é porque a cidade enquanto um direito (ótica de acesso) falhou para os trabalhadores formais, isso sem mencionar os informais ou desempregados que tal alternativa nunca entrou em debate.

E, no decorrer da pandemia a cidade tornou-se ainda mais hostil e inacessível para boa parcela dos trabalhadores que se depararam com os aumentos dos transportes, com a demanda ainda mais insuficiente do que sempre foi ofertado no cotidiano laboral e que arca com os seus próprios custos de locomoção. Ficamos com a indagação de que se a mobilidade urbana fosse diferente da posta para os trabalhadores em home office, e se fosse apresentado todas as questões que perpassam pelo home office (vantagens e desvantagens físicas e psicologias) e da implementação do teletrabalho, os trabalhadores ainda iriam optar por um cotidiano confinado que não há distinção entre a vida e trabalho.

\section{Considerações Finais}

84 A realidade cotidiana pretérita à pandemia, e até no pós-pandemia, nos faz projetar um futuro em abstração, coloca em lócus as desigualdades enfrentadas no trabalho e pelo trabalhador, pois as negações que foram discutidas na presente pesquisa passam pela mobilidade parcelar, pelo trabalho mal remunerado e chega até a cidade que não consegue atender as demandas necessárias para a realização da vida de forma digna.

O trabalho e a mobilidade do modo que são ofertados não consideram os trabalhadores enquanto cidadãos que buscam sobreviver na cidade, pois a ideia de direito se dissipa a qualquer tipo de avanço e de mudança das condições. Pois, de nada adianta converter 4 horas por dia no trânsito antes da pandemia, como foi levantado a partir de dos entrevistados que residem na Baixada Fluminense, e doar parte desse tempo que deveria ser de descanso para o cumprimento de horas-extras mal ou não remuneradas em home office.

O contexto da pandemia nos revê-la isso de modo alarmante, na tentativa de conciliar a sobrevivência dos trabalhadores em situação inadequada, no qual utilizam-se da quarentena como justificativa da adoção de medidas "delicadas" e da culpabilização da mobilidade urbana evidenciada pelos próprios trabalhadores - o que acaba sendo uma cortina de fumaça para implementar a diminuição de custos e direitos pelas empresas aos seus empregados.

87 Um importante tensionamento é refletir se os empregadores estão prevendo os danos físicos e mentais dos trabalhadores que realizam o home office, ou se minimamente asseguram o bem-estar ao fornecer equipamentos adequados. A realização do teletrabalho em home office deve acompanhar assistência técnica e trabalhista, visando 
os cuidados e custos que pode estar à cargo dos trabalhadores, pois parte dos entrevistados alegam que não possuem suporte para realizar as atividades e aqueles que receberam algum tipo de equipamento vê a necessidade de maior suporte.

A segurança do trabalho não é opcional. Para o bom funcionamento do ambiente de trabalho, é necessário manter condições salubres e adequadas objetivando o bem-estar do trabalhador, além de melhores garantias salariais, pois as baixas remunerações inserem os trabalhadores formais, em sua maioria, em uma vida doméstica parca e até insalubre.

Jornada tem capturado o tempo que deveria ser dedicado ao descanso, o convertendo em mais tempo de trabalho e precarização das condições de trabalho nos espaços laborais ou fora deles a partir da escassez material de condições básicas para a realização da vida e, assim, garantindo a vitalidade da força de trabalho.

Sob a ótica dos trabalhadores, a pesquisa realizou-se observando se o home office é alternativa viável de fuga das condições de trânsito, pois segundo os trabalhadores analisados, relataram unanimemente que a problemática da mobilidade é uma das maiores motivações para advogarem pela permanência do home Office. Mas, também, pode-se comprovar que, para os empregadores, as razões são outras e muito mais complexas ao solidificar essa prática ainda em status temporário, mas que pode tomar rumos para se tornar definitiva mesmo com inúmeras contradições.

91 Por fim, pode-se concluir com a pesquisa que o processo de alienação gerado pelo trabalho e a necessidade de obter meios de subsistência, em associação com os desafios urbanos, tem feito os trabalhadores repensarem as maneiras que lidam com as noções de ambiente de trabalho, coletividade, cotidiano laboral e garantias trabalhistas, que estão sendo amortecidas pela possibilidade de fuga do tempo gasto no trânsito da área metropolitana.

\section{BIBLIOGRAFIA}

BRASIL. Constituição. Constituição da República Federativa do Brasil. Brasília: Senado, 1988.

BRASIL. Lei Federal no 12.587, de 3 de janeiro de 2012. Institui as diretrizes da Política Nacional de Mobilidade Urbana; revoga dispositivos dos Decretos-Leis n. 3.326, de 3 de junho de 1941, e 5.405, de 13 de abril de 1943, da Consolidação das Leis do Trabalho (CLT), aprovada pelo Decreto-Lei no 5.452, de $1^{\circ}$ de maio de 1943, e das Leis n.o 5.917, de 10 de setembro de 1973, e 6.261, de 14 de novembro de 1975; e dá outras providências.

Disponível em: <http://www.planalto.gov.br/ccivil_03/_ato2011-2014/2012/lei/l12587.html>. Acessado em 9 novembro de 2020.

BRASIL, Decreto-Lei 5.452, de 1ํㅡㄴ maio de 1943. Aprova a Consolidação das Leis do Trabalho. Disponível em: <http://www.planalto.gov.br/ccivil_03/decreto-lei/del5452.htm>. Acessado em 12 dezembro de 2020.

BRASIL. Lei Federal n. 13.467, de 13 de julho de 2017. Altera a Consolidação das Leis do Trabalho

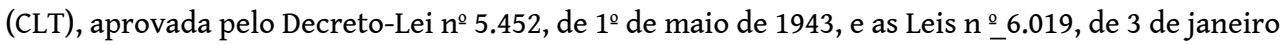


de 1974, 8.036, de 11 de maio de 1990, e 8.212, de 24 de julho de 1991, a fim de adequar a legislação às novas relações de trabalho. Disponível em: < http://www.planalto.gov.br/ccivil_03/ _ato2015-2018/2017/lei/l13467.htm>. Acessado em 01 novembro 2021.

ANTUNES, Ricardo. A dialética do trabalho: escritos de Marx e Engels. Vol. II. São Paulo: Expressão Popular, pp. 11-66, 2013.

. Adeus ao trabalho? Ensaio sobre as metamorfoses e a centralidade do mundo do trabalho. 16 ed. 3 reimpr. - São Paulo: Editora Cortez, 2015 [1995].

BARBOSA, Jorge. A mobilidade urbana no processo de metropolização: um ensaio crítico sobre as condições da condição social do espaço urbano no contemporâneo. In. FERREIRA, Álvaro; RUA, João; MATTOS, Regina (Org..). Desafios da metropolização do espaço. Rio de Janeiro: Editora Consequência, pp. 171-186, 2015.

. A mobilidade urbana como expressão do Direito à Metrópole. In. LIMONAD, Ester; CASTRO, Edna. Um novo planejamento para um novo Brasil? Rio de Janeiro: Letra Capital, pp. 190-205, 2014.

FALA! UNIVERSIDADES. Os extremos da mobilidade urbana Carioca (2020). Disponível em: $<$ https://falauniversidades.com.br/os-extremos-da-mobilidade-urbana-carioca/>. Acessado em 15 outubro de 2020 .

HARVEY, David. Neoliberalismo: histórias e implicações. 5 ed. - São Paulo: Editora Loyola, 2014.

INSTITUTO BRASILEIRO DE GEOGRAFIA E ESTATÍSTICA. Disponível em: < https:// covid19.ibge.gov.br/pnad-covid/trabalho.php>. Acessado em 11 dezembro de 2020.

LAGOS, Luciana. Trabalho, moradia e (i)mobilidade espacial na metrópole do Rio de Janeiro. Cadernos Metrópoles, v. 1, n. 18. pp. 275-293, 2007.

LÉVY, Jacques. Os novos espaços de mobilidade. Revista GEOgraphia. v. 3, n. 6, pp. 1-11, 2001[2000].

MASSON, Nathalia. Manual de direito constitucional. Salvador: Editora Juspodivm, pp. 208-216, 2016.

PERO, Valéria; MIHESSEN, Vitor. Mobilidade urbana e pobreza no Rio de Janeiro. Revista Econômica, v.15, n. 2, pp. 23-50, 2013.

RADIO AGÊNCIA NACIONAL. Pandemia agrava a situação do transporte público do RJ (2020). Disponível em: < https://agenciabrasil.ebc.com.br/radioagencia-nacional/acervo/geral/audio/ 2020-08/pandemia-agrava-situacao-do-transporte-publico-do-rj/>. Acessado em 16 outubro de 2020.

ROLNIK, Raquel. Teletrabalho não vai salvar nossa combalida mobilidade urbana. Disponível em: < http://www.labcidade.fau.usp.br/teletrabalho-nao-vai-salvar-nossa-combalida-mobilidadeurbana/>. Acessado em 12 outubro 2020.

SANTOS, Milton. O espaço do cidadão. - $7^{\mathrm{a}}$ ed. São Paulo: Editora da Universidade de São Paulo, 2014 [1987].

SEBRAE. Estudo Estratégico: Mobilidade urbana e Mercado de trabalho na RMRJ. Observatório Sebrae/RJ. - Rio de Janeiro: SEBRAE/RJ, 2013.

VALVERDE, Marina; SOUZA, Nathalia. O coronavírus e o trabalho remoto: é hora de levar o trabalho ao trabalhador. Disponível em: <https://uerjlabuta.com/2020/03/26/o-coronavirus-e-otrabalho-remoto-e-hora-de-levar-o-trabalho-ao-trabalhador/>. Acessado em 11 dezembro de 2020. 


\section{NOTAS}

1. Segundo o teletrabalho implementado na pandemia.

2. Período de realização da pesquisa submetida.

3. Ônibus, metrô, trem, barca, Veículo Leve sobre Trilhos (VLT), Bus Rapid Transit (BRT), entre outros, para acessarem seus postos de serviço;

4. Segundo a Política Nacional de Mobilidade Urbana, transporte público coletivo é serviço público de transporte de passageiros acessível a toda a população mediante pagamento individualizado, com itinerários e preços fixados pelo poder público; e, transporte coletivo: serviço de transporte de passageiros não aberto ao público para a realização de viagens com características operacionais exclusivas para cada linha e demanda.

5. Nove (9) encontram-se em situação de trabalho permanente e um (1) em situação de trabalho temporário.

6. Compreendemos que a Baixada Fluminense é composta pelos municípios de Belford Roxo, Duque de Caxias, Guapimirim, Itaguaí, Japeri, Magé, Mesquita, Nova Iguaçu, Nilópolis, Paracambi, Queimados e Seropédica, no Estado do Rio de Janeiro.

7. Em setor logístico de alimentos e bebidas, escritório de administração, escola, entre alguns outros que não quiseram identificar.

8. "Em 2018 o instituto Expert Market, dos Estados Unidos, divulgou uma pesquisa sobre a qualidade do transporte público realizada em 74 cidades em todo o mundo. A cidade do Rio de Janeiro ficou com a última posição entre as capitais mundiais." (FALA UNIVERSIDADES, 2020).

9. Em entrevista dada em janeiro de 2020 para o portal de notícias "Fala! Universidades" sobre "os extremos da mobilidade urbana carioca".

10. Obtemos apenas um (1) trabalhador que utiliza o seu meio de transporte particular (carro) e os outros nove (9) se valem de diferentes tipos de transporte coletivo para acessarem os seus locais de trabalho ou regressarem aos seus lares antes da pandemia.

11. Os dados utilizados são aqui colocados pela ausência de realização de um novo Censo, mas que deve (entanto possibilidade) ser realizado em 2022.

12. No Brasil, o termo é utilizado para os horários em que há um grande quantitativo pessoas circulando.

13. Segundo as CLT, o tempo despendido pelo empregado desde a sua residência até a efetiva ocupação do posto de trabalho e para o seu retorno, caminhando ou por qualquer meio de transporte, inclusive o fornecido pelo empregador, não será computado na jornada de trabalho, por não ser tempo à disposição do empregador.

\section{RESUMOS}

É com o intento de compreender algumas questões relativas ao trabalho, trabalhador e a (i)mobilidade urbana na Cidade do Rio de Janeiro que a presente pesquisa é tecida. Buscar-se-á analisar o home office (em conjunto com o teletrabalho) enquanto alternativa de fuga do tempo gasto no trânsito, perpassando debates acerca das atribuições empregatícias ainda omitidas pelos empregadores, negando garantias trabalhistas e provisão de suporte para a realização da prática laboral em domicílio no ano de 2020. Pode-se comprovar que a questão espacial tem grande relevo para analisar a circulação e fluxos dos trabalhadores, e com o decorrer da pandemia a adesão ao home office pelo trabalhador como prática permanente é impulsionada pela 
problemática da (i)mobilidade da área metropolitana do Rio de Janeiro. Por fim, acredita-se que, assim, a Geografia pode contribuir ao debate urbano acerca de aspectos do cotidiano do trabalhador em tempos de covid-19.

It is with the intent of understanding some issues related to work, workers and urban (i)mobility in the City of Rio de Janeiro that this research is woven. It will seek to analyze the home office (together with teleworking) as an alternative to escape the time spent in traffic, going through debates about the employment attributes still omitted by employers, denying labor guarantees and provision of support for the realization of the work practice at home in the year 2020. It can be proven that the spatial issue has great relevance to analyse the circulation and flows of workers, and with the course of the pandemic, the adhesion to the home office by the worker as a permanent practice is driven by the problem of (i)mobility of the metropolitan area of Rio de Janeiro. Finally, it is believed that, in this way, Geography can contribute to the urban debate about aspects of the worker's daily life in times of covid-19.

Cet article analyse le home office (à côté du télé-travail) comme une alternative au temps de déplacement professionnel dans la Région Métropolitaine de Rio de Janeiro. Sans oublier les questions liées aux responsabilités des employeurs et les garanties aux ouvriers tels que le support nécessaire au travail doméstique, on montre que la question spaciale est essentielle pour comprendre la circulation et les flux des travailleurs dans une Région Métropolitaine marquée par l'i-mobilité. Enfin, on souligne que la géographie peut contribuer aux débats relatifs au quotidian des ouvriers urbains en temps de Covid-19.

Es con la intención de comprender algunos temas relacionados con el trabajo, el trabajador y la (i)movilidad urbana en la Ciudad de Río de Janeiro que se teje esta investigación. El objetivo será analizar el home office (junto con el teletrabajo) como una alternativa para escapar del tiempo de tránsito, pasando por debates sobre las atribuciones laborales aún omitidas por los empleadores, negando garantías laborales y brindando apoyo para el desempeño de la práctica laboral. en residencia en 2020. Se puede apreciar que el tema espacial es de gran importancia para analizar la circulación y los flujos de trabajadores, y con el transcurso de la pandemia, la adhesión al home office por parte del trabajador como práctica permanente es impulsada por el problema de (i) movilidad em el área metropolitana de Río de Janeiro. Finalmente, se cree que, de esta manera, la Geografía puede contribuir al debate urbano sobre aspectos de la vida cotidiana del trabajador en tiempos del covid-19.

\section{ÍNDICE}

Mots-clés: mobilité ; home office ; télétravail ; travailleur ; Rio de Janeiro

Palabras claves: movilidad; home office; teletrabajo; trabajador; Rio de Janeiro

Palavras-chave: mobilidade; home office; teletrabalho; trabalhador; Rio de Janeiro

Keywords: mobility; home office; teleworking; workers; Rio de Janeiro

\section{AUTOR}

\section{FLÁVIA DA SILVA SOUZA}

Mestre em Geografia pela UFRRJ, Doutoranda do Programa de Pós-graduação em Geografia (PPGEO) da Universidade do Estado do Rio de Janeiro (UERJ) e Bolsista da Coordenação de Aperfeiçoamento de Pessoal de Nível Superior (CAPES). E-mail: flaviasouza1993@gmail.com 